\title{
GEOTECHNICAL PROPERTIES OF LATERITIC SOIL STABILIZED WITH CASSAVA PEEL ASH AND STEEL DUST
}

\author{
Olaniyan, O.S \\ Department of Civil Engineering, \\ Ladoke Akintola University of Technology, Ogbomoso, \\ Oyo State, Nigeria
}

\author{
Agbeluyi, T.O \\ Department of Civil Engineering, \\ Ladoke Akintola University of Technology, Ogbomoso \\ Oyo State, Nigeria
}

\author{
Adegbola, A. A \\ Department of Civil Engineering, \\ Ladoke Akintola University of Technology, Ogbomoso, \\ Oyo State, Nigeria
}

\begin{abstract}
The management of solid waste like steel dusts is a major challenge in Nigeria. Cassava Peel Ash (CPA) is a good pozolan as established from past studies. In this study, the geotechnical properties of weak lateritic soil stabilized with CPA and steel chips was investigated.

Cassava peels of variety UMUCASS42 were collected from a local cassava processing factory in OkeBaale, Osogbo, Osun State. They were sundried, calcinated at $700^{\circ} \mathrm{C}$ and its chemical composition (Calcium, Silicon, Iron and Aluminium Oxides) were determined using $\mathrm{X}$ Ray Fluorescence (XRF) Analyzer. Three lateritic soils samples $A, B$ and $C$ from $7^{\circ} 28^{\prime} 46^{\prime \prime} N 4^{\circ} 34^{\prime} 45^{\prime \prime} E, 7^{\circ} 34^{\prime} 55^{\prime \prime} \mathrm{N}$ $4^{\circ} 24^{\prime} 47^{\prime \prime} \mathrm{E}$ and $7^{\circ} 44^{\prime} 54^{\prime \prime} \mathrm{N} 4^{\circ} 31^{\prime} 10^{\prime \prime} \mathrm{E}$, respectively were used. The geotechnical properties which included Moisture Content, Specific Gravity, Particle Size Analysis (percentage passing sieve no 200), Plastic Index (PI), Optimum Moisture Content (OMC), Maximum Dry Density (MDD) and California Bearing Ratio (CBR) of lateritic soil were determined at natural state. The lateritic soils were stabilized at $4 \%$ fixed steel dusts and at $0,2,4,6$ and $8 \%$ of CPA by dry unit weight of the soil samples. The MDD, CBR, OMC and Unconfined Compressive Strength (UCS) of the stabilized lateritic soil samples were determined. Analysis of Variance (ANOVA) at 5\% level of significance was used to determine the effects of varying percentage of CPA with steel chips.

The Calcium, Silicon, Iron and Aluminium Oxide of $\mathrm{CPA}$ at $700^{\circ} \mathrm{C}$ were $10.51,60.67,4.91$ and $4.56 \%$, respectively. The natural moisture content, specific gravity, percentage passing sieve no 200, PI, OMC, MDD and CBR of soil samples $A, B$ and $C$ were $15.1 \%, 2.73$, $42.1 \%, 11.3 \%, 22.2 \%, 1846 \mathrm{~kg} / \mathrm{m}^{3}, 6 \% ; 10.1 \%, 2.8$, $50.8 \%, 7.7 \%, 19.6 \%, 1702 \mathrm{~kg} / \mathrm{m}^{3}, 2 \%$ and $13.8 \%, 2.65$, $42.1 \%, 11.3 \%, 15.1 \%, 2880 \mathrm{~kg} / \mathrm{m}^{3}, 4 \%$, respectively. The
\end{abstract}

corresponding values for MDD, CBR, OMC and UCS of stabilized soil samples $A, B$ and $C$ varied from 1938-2042 $\mathrm{kg} / \mathrm{m}^{3}, 8-10 \%, 18.4-22.2 \%, 186-305 \mathrm{kN} / \mathrm{m}^{2} ; 1935-2144$ $\mathrm{kg} / \mathrm{m}^{3}, 4-6 \%, 16.8-19.6 \%, 195-295 \mathrm{kN} / \mathrm{m}^{2}$ and $2880-3020$ $\mathrm{kg} / \mathrm{m}^{3}, 5-8 \%, 11.8-15.1 \%, 159-230 \mathrm{kN} / \mathrm{m}^{2}$, respectively. There was significant effect of varying percentage of admixture (CPA and steel chips) for stabilization on PI (P $=0.1986>0.05$ ).

The composite of CPA and steel chips is a good stabilizer for poor lateritic soil. Stabilization of weak lateritic soil with $4 \%$ of the composite can be used for base course in highway construction work.

Keywords - Cassava, steel chips, laterite, stabilization

\section{INTRODUCTION}

In Nigeria, there has been a recent spade in the rate of failure of roads and other structural entities. This has led to an up rise in the number of accidents and loss of both lives and properties. A major contributing factor to this increase in accidents is the poor nature / condition of the roads and highways present within the country. Besides the abuse of roads by truck and other road users, highway engineers have discovered that the failure of these roads occur as a result of bad or insufficient materials used as sub grade, sub base and sometimes base layers during construction $[5,12,13,14]$.

As a result, research in the past years has been carried out on how to improve the engineering properties of soils. Along this line, stabilization of subgrade material has been used as an efficient means of improving the quality of Nigerian roads. However, the available soils do not have adequate engineering properties to really bear the expected wheel load applied on them, there by resulting in improvisations to be made so as to make these soil better and 
more adequate to resist the axle wheel had which will be applied on them after construction. The concept of making the soil better is called soil stabilization [8 -11].

However, cassava peel constitutes between $20-35 \%$ of the weight of fiber, especially in the case of hand peeling. Based on $20 \%$ estimate, about 6.8 million tones of cassava peel is generated annually and 12 million tones are expected to be produced in the year 2020. Indiscriminate disposal of cassava peels due to gross under-utilization as well as lack of appropriate technology to recycle them in is a major challenge, which results in environmental problem [1,2]. Steel dust is a product from grinding operation of ferrous metals which constitute to environmental nuisance if not properly handled.

\section{MATERIAL AND METHODS}

This research work entails assessing the effect of cassava peel ash (CPA) with steel dust on the geotechnical properties of some selected lateritic soil. These geotechnical properties include liquid limit (LL), plastic limit (PL), plasticity index (PI), compaction, California bearing ratio (CBR) and Unconfined Compressive strength (UCS).

These tests were carried out in accordance with outlined procedures in BS 812-102:1984, BS 812-103.1:1985 and BS 1377 part 2-4 (1990) on both natural and stabilized lateritic soil samples. Two ways analysis of variance (ANOVA) without replication" was used to test if there are significant difference on the geotechnical properties measured against the three different locations and the level of CPA with steel added to the soil. For the stabilized lateritic soil samples, the CPA was introduced in incremental order of $12,14,16,18$ and $20 \%$ by dry unit weight of the soil samples with a fixed percentage of $4 \%$ steel scraps by dry unit weight of the soil samples so as to enhance soil reinforcement.

Three lateritic soil samples labelled A, B, C were collected from three different locations in Osun state, Nigeria with a GPS location of $7^{\circ} 28^{\prime} 46^{\prime \prime} \mathrm{N}, 4^{\circ} 34^{\prime} 45^{\prime \prime} \mathrm{E}$ in Ife-East Local Government; Oogi borrow pit $7^{\circ} 34^{\prime} 55^{\prime \prime} \mathrm{N}, 4^{\circ} 24^{\prime} 47^{\prime \prime} \mathrm{E}$ in Ayedaade Local government and $7^{\circ} 44^{\prime} 54^{\prime \prime} \mathrm{N}, 4^{\circ} 31^{\prime} 10^{\prime \prime} \mathrm{E}$ in Olorunda Local Government, respectively. Cassava peels used in this study was collected from a local cassava processing factory in Oke-Bale, Osogbo, Osun State, Nigeria. The steel dust was from grinding operation obtained from crankshaft grinding shop in Saw mill area, Ogbomoso.

The equipments used for the laboratory tests were: Atterberg limit apparatus, $\mathrm{pH}$ meter, digital weighing balance, and set of standard sieves with opening ranging from $75 \mu \mathrm{m}$ to $4.75 \mathrm{~mm}$, including a cover plate and bottom pan. Other equipment used were: electric furnace $\left(1200^{\circ} \mathrm{C}\right)$, electric oven $\left(105^{\circ} \mathrm{C}\right.$ to $\left.500^{\circ} \mathrm{C}\right)$, modified proctor mould, triaxial machine and California Bearing Ratio (CBR) machine.

\section{a. Natural Moisture Content -}

Soil samples $(0.2 \mathrm{~kg}$ each) were crumbled and placed loosely in a clean can. The weight of can was measured to the nearest $0.1 \mathrm{~g}$ and recorded as $\mathrm{M}_{1}$. The can and its content was weighed and recorded as $\mathrm{M}_{2}$, and then placed in the oven to dry at $105^{\circ} \mathrm{C}$ to $110^{\circ} \mathrm{C}$ for 24 hours. After this drying period the can and its content was removed to cool. The can and its content was weighed and recorded as $\mathbf{M}_{3}$. In the computation, the moisture contents of the soil samples were expressed as percentage of the dry soil samples. The moisture content was computed from equation 1

$$
w=\frac{M_{2}-M_{2}}{M_{2}-M_{2}} \times 100 \%
$$

Where:

$M_{1}=$ weight of the empty can $(\mathrm{g})$

$M_{2}=$ weight of wet soil + can $(\mathrm{g})$

$M_{3}=$ weight of dry soil + can $(\mathrm{g})$

\section{b. Particle Size Distribution}

Particle size analysis test involves shaking the soil sample through a set of stacked sieves arranged in descending order. The soil was washed and oven dried before passing it through the set of sieves. The following sieves number was used: 4, 10, 16, 20, 40, 60, 100 and 200 as well as a receiving pan. The respective weights of the sieves were taken and recorded. The washed samples (200g each) which have been oven dried above $100^{\circ} \mathrm{C}$ were the stacked sieves and vibrate electronically for 15 minutes. Each sieve together with its content was weighed and recorded. The test was carried out in accordance with the procedure outlined in BS 1377-2 1990.

\section{c. Specific Gravity (SG)}

$100 \mathrm{~g}$ of dried soil samples sieved through $425 \mu \mathrm{m}$ opening was obtained. A density bottle of 1 litre capacity with a rubber cork was cleaned, dried, weighed and recorded as $\mathrm{W}_{1}$. The cork was removed, and the sample was poured into the bottle. The cork was replaced, weighed and recorded as $\mathrm{W}_{2}$. Distilled water was poured into the bottle until it was halffilled with the water and topped by the cork. The bottle was vigorously shaken in other to form a suspension, and finally the bottle filled to the brim with the water, the density bottle with the rubber cork was be wiped dry, weighed and recorded as $\mathrm{W}_{3}$.

The density bottle content was emptied and rinsed with distilled water, it was then filled with distilled water only and rubber cork replaced, wiped dry, weighed and recorded as $\mathrm{W}_{4}$. The procedure was repeated for each of the soil samples. The accuracy of weighing was carefully achieved at all stages and Specific gravity estimated using equation 2

$$
\begin{aligned}
& \mathrm{SG}=\frac{\left(W_{2}-W_{2}\right)}{\left(W_{2}-W_{2}\right)-\left(W_{2}-W_{4}\right)} \\
& \text { Where: } \\
& W_{1}=\text { weight of the empty density bottle }(\mathrm{g})
\end{aligned}
$$


$W_{2}=$ weight of dry soil + density bottle $(\mathrm{g})$

$W_{3}=$ weight of soil + water + density $(\mathrm{g})$

$W_{4}=$ weight of water + density $(\mathrm{g})$.

\section{d. Atterberg Limits}

Atterberg limits are basic measure of the nature of fine grained fraction of a soil which passes through sieve size $425 \mu \mathrm{m}$. The test here includes liquid limit (LL), the plastic limit (PL) and the Plasticity Index (PI). These wiERE determined for the natural soil samples of all the three samples using the standard procedure in accordance with BS 1377-2 1990.

In carrying out the liquid limit test, $150 \mathrm{~g}$ of the soil samples passing $425 \mu \mathrm{m}$ was mixed thoroughly with distilled water using spatula until the mix formed a uniform paste. A small sample of the mixed soil was placed in the LL device. Using a cutting groove to cut through the centre of the placed soil sample in the cup, the LL device was run and the number of blows $(\mathrm{N})$ required to close this groove through a distance of $13 \mathrm{~mm}$ was counted and recorded. About $10 \mathrm{~g}$ of the paste was taken from the two sides of the paste in the cup into the can and oven dried for 24 hours to determine the moisture content. The test was repeated three times $[\mathrm{N} \sim(10-20), \mathrm{N} \sim(20$ 30) and $\mathrm{N} \sim(35-45)]$ and the logarithmic graph of number of blows against moisture content for the three soil samples was plotted. The liquid limits (LL) was determined at moisture content at 25 blows.

A representative sample of about $50 \mathrm{~g}$ was taken from the remainder of soil sample used in the liquid limit determination. This was thoroughly mixed with distilled water on a glass plate until it became sufficiently plastic enough to be moulded into ball. The ball of soil was rolled between the palms until slight hair-line cracks appeared at the surface. The ball sample was splitted into two samples. These two samples was further be divided into four equal parts and each part was be rolled into a $3 \mathrm{~mm}$ diameter thread. Two cans of rolled soil samples was used for the test so as to eliminate inaccuracies.

\section{e. Preparation of CPA and Steel Dust}

The collected cassava peel was air dried for a period of two weeks thereby ensuring total dryness. The dried peels were calcined at a temperature of $700^{\circ} \mathrm{C}$ for 90 minutes by using electric furnace. The clinker was grounded to fine powder and passed through BS sieve No. $40(425 \mu \mathrm{m}$ sieve opening) to get very fine ash which was stored in an air tight container to prevent moisture loss and any form of contamination. Steel dust was collected, thoroughly washed, dried and sieve through sieve no 40 was used in this study.

The physiochemical properties such as the $\mathrm{pH}$ and chemical compositions of the CPA were determined using $\mathrm{pH}$ meter in accordance with BS 1377: 1990: Part 3: 9.5 and Atomic Absorption Spectroscopy (AAS) technique, respectively.

The geotechnical tests considered in this study are: Atterberg tests (LL, PL, and PI) and the strength tests (Compaction test, California Bearing Ratio (CBR) and the
Unconfined compression strength test). For the index property tests, they were conducted using standard method in accordance with BS 1377-2 1990. Each and every test was conducted with the appropriate mix percentage of CPA which was compared with control specimens. The strength property tests such as compaction, CBR and UCS were carried out using the method outlined in BS 1377 - Part 4 -90. Each and every test was conducted with various mix percentage of the soil with CPA. The results obtained were analyzed and compared with control specimens.

\section{RESULT AND DISCUSSION}

The natural moisture content of the selected soil samples A, $\mathrm{B}$ and $\mathrm{C}$ were $15.1,10.1$ and $13.8 \%$, respectively. This implies that the soil samples at its natural state contain some amount of moisture, which is influenced by the climate conditions such as temperature, rainfall intensity, and evaporation. The specific gravity of sample A, B and C are 2.73, 2.80 and 2.65, respectively. Das (2010) showed specific gravity of clay mineral as: montmorillonite (2.65 to 2.8), Biotite (2.8 to 3.2) and Halloysites (2.0 to 2.55). Sample A, B and C contain montimorrilonite and biotite based on their specific gravity. The preliminary analysis of soil samples used is presented in Table 1.

Table 1: Summary of the Preliminary Analysis of Soil Samples

\begin{tabular}{clll}
\hline ITEM & A & B & C \\
\hline Natural Water Content (\%) & 15.1 & 10.1 & 13.8 \\
pH & 4.7 & 5.7 & 4.6 \\
Specific Gravity & 2.73 & 2.80 & 2.65 \\
Percentage Passing Sieve No. 40 & 65.4 & 69.4 & 65.5 \\
$\begin{array}{c}(\%) \\
\text { Percentage Passing Sieve No. 200 } \\
(\%)\end{array}$ & 42.1 & 50.8 & 42.1 \\
Liquid Limit (LL) \% & 42.9 & 55.3 & 42.8 \\
Plastic Limit (Pl) \% & 31.6 & 47.6 & 31.5 \\
Plasticity Index (PI) \% & 11.3 & 7.7 & 11.3 \\
OMC (\%) & 22.2 & 19.6 & 15.1 \\
MDD (kg/m $\left.{ }^{3}\right)$ & 1846 & 1702 & 2880 \\
CBR (\%) & 6.0 & 2.0 & 4.0 \\
UCS (kN/m $\left.{ }^{2}\right)$ & 180 & 195 & 159 \\
AASHTO Classification & A-7-5 & A-5 & A-7-5 \\
USCS & SC & SM & SC \\
\hline
\end{tabular}


The three soil samples are considered as silty-clay materials because more than $35 \%$ of their soil materials were finer than $75 \mu \mathrm{m}$, while soil sample B was classified as A-5 and considered as silty soil. Sample A and C are clayey soil because more than $35 \%$ of its material is finer than $75 \mu \mathrm{m}$ sieve. Sample A and C have Plastic Index (PI) of 11.3 and are clayey because $\mathrm{PI}>11 \%$ according to AASHTO. Sample B is silty because its $\mathrm{PI}<10 \%$. Samples $\mathrm{A}$ and $\mathrm{C}$ have medium plastic fines (Clayey sand) while sample B has fines with high plasticity.

The particle size distribution curves of samples $\mathrm{A}$ and $\mathrm{C}$ are similar due to the fact that they contain more clayey particles while sample B is silty as shown in Figure 1. The compaction characteristic of the soil in their natural state is shown in Figure 2.

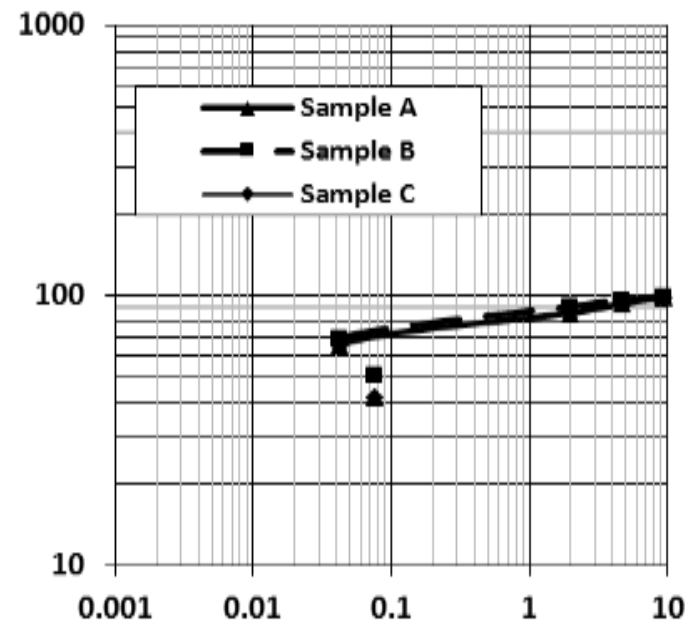

Figure 1: Particle size Distribution Curve for the Soil samples

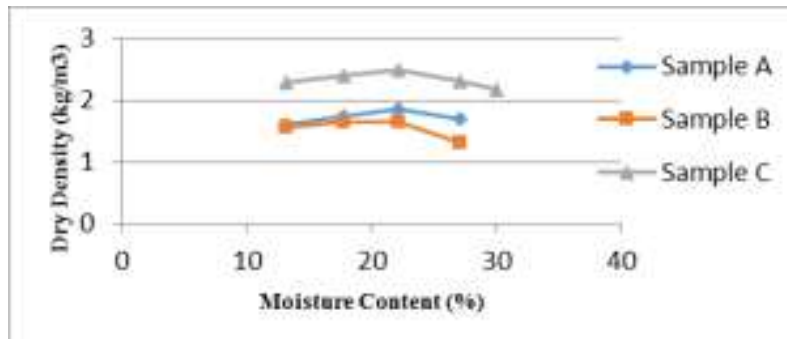

Figure 2: Compaction characteristic of Soil samples in their Natural states

The CBR of the soil samples A, B, and C are 6.0, 2.0 and $1.0 \%$, respectively. The Asphalt Institute (1962) as cited in [11] recommended a CBR of $(7-20) \%$ and $(0-7) \%$ for highway sub base and sub grade material, respectively. Based on this, the three soil samples are considered neither good to be used as sub grade or sub-base materials material. The load bearing capacity of the entire soil samples are not adequate to be used for highway construction purposes.

The $\mathrm{pH}$ and the oxide composition of the soil samples and CPA obtained from the chemical analysis are presented in Table 2. The $\mathrm{pH}$ of the three soil samples shows that they are all acidic which is typical of laterites [3, 6]. The percentage composition of Calcium and Silicate Oxides $\left(\mathrm{CaO}\right.$ and $\left.\mathrm{SiO}_{2}\right)$ obtained in CPA agrees with the results obtained by [2].

Table 2: Chemical Composition of CPA and Soil Samples

\begin{tabular}{cccc}
\hline Sample & $\mathbf{p H}$ & $\mathbf{C a O}(\boldsymbol{\%})$ & $\mathbf{S i O}_{\mathbf{2}}(\boldsymbol{\%})$ \\
\hline $\mathrm{A}$ & 4.6 & 0.003 & 40.17 \\
$\mathrm{~B}$ & 5.7 & 0.006 & 41.03 \\
$\mathrm{C}$ & 4.1 & 0.015 & 39.24 \\
$\mathrm{CPA}$ & 11.3 & 12.51 & 35.67 \\
\hline
\end{tabular}

The Atterberg Limit for the stabilized samples is presented in Table 3. The summary of the CBR and UCS results are presented in Tables 4 and 5.

\section{Compaction Results}

The results of this study showed increase in MDD in agreement with $[3,12]$. For all the treated soil samples, MDD increased as the percentage of CPA increased. The increased values tend to fluctuate however, for all the soil samples. Bell (1993) reported that, the addition of lime to clayey soils increases the OMC and reduces the MDD for the same compactive effort. The MDD of the soil samples treated with lime were lower while the OMC of the treated soil samples were higher than that of the untreated samples as reported in $[9,10]$. However, for soil samples treated with lime, both the OMC and MDD of the treated soil samples increased.

Compaction results also revealed that no optimum CPA content was obtained. This is because the MDD kept increasing for the three soil samples as the \% of CPA increased. This implies that the MDD might still be increasing as the $\%$ ash increased beyond $8 \%$ (which is the limiting value in this study).

The CBR results for both sample A, B and C show that optimum CPA content was $4 \%$ which produce the maximum value of $\mathrm{CBR}$ in all samples. Any further addition in the \%CPA beyond $4 \%$ tends to decrease the CBR value. Therefore, the optimum \% of CPA for sample $\mathrm{C}$ is $4 \%$ based on the highest $\mathrm{CBR}$ value.

Considering the results of the UCS for the soil samples, no optimum CPA content was obtained for both samples A, B and C due to the increment in UCS as \% CPA increased. This increment might still continue beyond the $8 \%$ CPA content which is the limiting value in this study. These results imply that the addition of CPA does have significant effect on the UCS as indicated by P values lower than 0.05 . 


\section{Table 3: Atterberg Limit Results}

\begin{tabular}{|c|c|c|c|c|}
\hline $\begin{array}{c}\text { Sam } \\
\text { pl. }\end{array}$ & $\begin{array}{c}\text { Percentage } \\
\%\end{array}$ & $\begin{array}{c}\mathbf{L L} \\
\%\end{array}$ & $\begin{array}{c}\text { PL } \\
\%\end{array}$ & (PI) \% \\
\hline \multirow{5}{*}{ A } & $\begin{array}{c}\text { Natural Soil } \\
\text { Alone }\end{array}$ & 42.9 & 31.6 & 11.3 \\
\hline & $2 \%$ CPA & 43.1 & 30.2 & 12.9 \\
\hline & $4 \% \mathrm{CPA}$ & 43.8 & 29.8 & 14.0 \\
\hline & $6 \%$ CPA & 43.9 & 30.1 & 13.8 \\
\hline & $8 \%$ CPA & 43.8 & 29.5 & 14.3 \\
\hline \multirow{5}{*}{ B } & $\begin{array}{c}\text { Natural Soil } \\
\text { Alone }\end{array}$ & 55.3 & 47.6 & 7.7 \\
\hline & $2 \%$ CPA & 55.7 & 47.4 & 7.9 \\
\hline & $4 \% \mathrm{CPA}$ & 55.1 & 46.9 & 8.2 \\
\hline & $6 \% \mathrm{CPA}$ & 54.6 & 46.1 & 8.5 \\
\hline & $8 \% \mathrm{CPA}$ & 55.4 & 45.9 & 9.5 \\
\hline \multirow{5}{*}{$\mathrm{C}$} & $\begin{array}{l}\text { Natural Soil } \\
\text { Alone }\end{array}$ & 42.8 & 31.5 & 11.3 \\
\hline & $2 \% \mathrm{CPA}$ & 43.0 & 31.1 & 11.9 \\
\hline & $4 \% \mathrm{CPA}$ & 43.4 & 30.6 & 12.8 \\
\hline & $6 \%$ CPA & 43.9 & 29.6 & 14.3 \\
\hline & $8 \%$ CPA & 43.6 & 29.8 & 13.8 \\
\hline
\end{tabular}

\section{CONCLUSION AND RECOMMENDATION} study:

The following conclusions were made from this

(i) $\quad \mathrm{CPA}$ is a pozolan with silicate oxides in sample A, B, C and CPA as 40.17, $41.03,39.24$ and $35.67 \%$, respectively.

(ii) All the samples considered in this study are rated as poor for base, subase and subgrade construction work

(iii) . The value of CBR was at optimum value at 4\% CPA in samples A, B and C. In all the samples, the UCS increases as the $\%$ CPA increases.

(iv) The Optimum percentage that produce the maximum strength is $4 \% \mathrm{CPA}$

\section{Recommendation for Further Study}

Based on the findings of this research work, the

following recommendations are made:

i. the quantity of CPA should be increased beyond $8 \%$ to ascertain the optimum percentage required for soil stabilization;

ii. the composite (CPA and steel scraps) can be a good stabilizer in poor lateritic soil that is less clayey.

\section{REFERENCE}

[1] Adesanya, O. A.,Oluyemi K. A., Josiah, S. J., Adesanya, R. A.,Shittu, L. A.,Ofusori, D. A., Bankole, M. A. and Babalola, G. B. (2008). Ethanol Production by Saccharomyces Cereviasiae from Cassa Peel Hydrolysate. The International Journal of Microbiology_5(1), 25-35.

[2] Agbenyeku, E. E. and Aneke, I. F. (2014). Prolong Curing of Green Concrete from Domestically Dried Cassava Peels Ash and Laterite. International Journal of Scientific and Engineering Research, 5(1) 2229 - 5518.

[3] Amu, O. O., Ogunniyi, S. A. and Oladeji, O. O. (2011b).Geotechnical properties of lateritic soil stabilized with sugarcane straw ash. American Journal of Scientific and industrial Research 2(2), 323-331.

[4] Ayodele, A. L. (2014). A Study of Electrochemical Treatment of Typical Soft Lateritic Soil, Ph.D. Thesis, Department of Civil Engineering, Obafemi Awolowo University, Ile-Ife.

[5] Jegede, G. (2000). Effect of Soil Properties on Pavement Failures along the F209 Highway at Ado Ekiti, South Western Nigeria. Construction and Building Materials.Vol. 14, 311315.

[6] Maher, A., Bennert, T., Jafari, F., Doglas, W.S. and Gucunski, N. (2004). Geotechnical Properties of Stabilized Dredged Material from New York - New Jersey Harbor. Journal of the Transportation Research Board, 86-96.

[7] Medjo, E. and Riskowiski, G. (2004). A procedure for processing mixtures of soil, cement, and sugar cane bagasse. The Journal of Scientific Research and Development. vol 3: 15.

[8] Osinubi K.J. (2000). Laboratory trial of soil stabilization using pulverized Coal Bottom Ash. NSE Transaction. 35(4): 13-21.

[9] Osinubi, K. J.and Eberemu, A. O. (2009). Desiccationinduced Shrinkage of Compacted Lateritic Soil treated with bagasse ash.Twenty-Fourth International Conference on Solid Waste Technology and Management, 856-867.

[10] Osinubi, K.J. and Stephen, T.A. (2006). Effect of curing period on bagasse ash Stabilized black cotton soil. Book of Proc. Bi-monthly Meetings/Workshop, Material Society of Nigeria. 1-8.

[11] Ogunribido, T.H.T. (2012). Geotechnical Properties of Saw Dust Ash Stabilized Southwestern Nigeria Lateritic Soils. 
Environmental Research Engineering and Management, 2 (60), 29-33.

[12] Otoko, G. R. and Karibo, P. (2014). Stabilization of Nigerian Deltaic Clay (Chikoko) with Groundnut Shell. International Journal of Engineering and Technology Research, 2 (6): 53 - 60.

[13] Pendelton, R. L. and Sharasuvana. (1994). Analysis of Some Siamese Laterites, Soil Science. 62, 423-440.

\begin{tabular}{ccc}
$4 \% \mathrm{CPA}+4 \% \mathrm{SD}$ & 255.0 \\
$6 \% \mathrm{CPA}+4 \% \mathrm{SD}$ & 280.0 \\
$8 \% \mathrm{CPA}+4 \% \mathrm{SD}$ & 295.0 \\
\hline $\mathrm{C}$ & Natural Soil Alone & 159.0 \\
$0 \% \mathrm{CPA}+4 \% \mathrm{SD}$ & 125.0 \\
$2 \% \mathrm{CPA}+4 \% \mathrm{SD}$ & 170.0 \\
$4 \% \mathrm{CPA}+4 \% \mathrm{SD}$ & 215.0 \\
& $6 \% \mathrm{CPA}+4 \% \mathrm{SD}$ & 205.0 \\
& $8 \% \mathrm{CPA}+4 \% \mathrm{SD}$ & 230.0 \\
\hline
\end{tabular}

[14] Prusinski, J.R., and Bhattacharja, S. (1999). Effectiveness of Portland Cement and Lime in Stabilizing Clay Soils, National Research Council,Washington, D.C, 215-227.

[15] Serajuddin, M. and Azmal, M. (1991). Fine-grained soils of Bangladesh for Road Construction, Proc., 9th ARC on Soil Mechanics and Foundation Engineering, Bangkok, 1: 175-178.

NOTE SD: Steel Dust

Table 4: Summary of CBR Result

\begin{tabular}{|c|c|c|}
\hline Samples & $\begin{array}{c}\text { Percentage } \\
\text { stabilization }(\%)\end{array}$ & CBR (Unsoaked) (\%) \\
\hline $\mathrm{A}$ & $\begin{array}{l}\text { Natural Soil Alone } \\
0 \% \text { CPA }+4 \% \text { SD } \\
2 \% \text { CPA }+4 \% \text { SD } \\
4 \% \mathrm{CPA}+4 \% \text { SD } \\
6 \% \mathrm{CPA}+4 \% \text { SD } \\
8 \% \mathrm{CPA}+4 \% \mathrm{SD}\end{array}$ & $\begin{array}{c}6.0 \\
8.0 \\
10.0 \\
11.0 \\
10.0 \\
9.0 \\
\end{array}$ \\
\hline B & $\begin{array}{l}\text { Natural Soil Alone } \\
0 \% \mathrm{CPA}+4 \% \mathrm{SD} \\
2 \% \mathrm{CPA}+4 \% \mathrm{SD} \\
4 \% \mathrm{CPA}+4 \% \mathrm{SD} \\
6 \% \mathrm{CPA}+4 \% \mathrm{SD} \\
8 \% \mathrm{CPA}+4 \% \mathrm{SD}\end{array}$ & $\begin{array}{l}2.0 \\
4.0 \\
5.0 \\
6.0 \\
6.0 \\
5.0\end{array}$ \\
\hline $\mathrm{C}$ & $\begin{array}{l}\text { Natural Soil Alone } \\
0 \% \text { CPA }+4 \% \text { SD } \\
2 \% \text { CPA }+4 \% \text { SD } \\
4 \% \text { CPA }+4 \% \text { SD } \\
6 \% \text { CPA }+4 \% \text { SD } \\
8 \% \text { CPA }+4 \% \text { SD }\end{array}$ & $\begin{array}{l}4.0 \\
5.0 \\
6.0 \\
8.0 \\
8.0 \\
6.0\end{array}$ \\
\hline
\end{tabular}

Table 5: Summary of UCS Result

\begin{tabular}{ccc}
\hline Samples & $\begin{array}{c}\text { Percentage stabilization } \\
(\mathbf{\%})\end{array}$ & $\mathbf{U C S}(\mathbf{q u})$ \\
& $\mathbf{k N} / \mathbf{m}^{\mathbf{2}}$ \\
\hline $\mathrm{A}$ & Natural Soil Alone & 180.0 \\
& $0 \%$ CPA + 4 \% SD & 186.0 \\
& $2 \%$ CPA + 4\% SD & 198.0 \\
& $4 \%$ CPA + 4\% SD & 239.0 \\
& $6 \%$ CPA + 4\% SD & 275.0 \\
& 8\% CPA +4\% SD & 305.0 \\
\hline B & Natural Soil Alone & 195.0 \\
& 0 \% CPA + 4 \% SD & 205.0 \\
& $2 \%$ CPA + 4\% SD & 219.0
\end{tabular}

